\title{
Health Beliefs in a Population: The Michigan Blood Pressure Survey
}

\author{
Joel L. Weissfeld, MD \\ John P. Kirscht, PhD \\ Bruce M. Brock, PhD
}

In a general population sample, we examined relationships between sociodemographic characteristics and health beliefs. Individual questionnaire measures for components of the health belief model were combined to form six scales. In analyses which adjusted for perceived levels of health, sociodemographic markers of social disadvantage (e.g., black race, or low socioeconomic status) appeared to associate with favorable health beliefs, that is, with health beliefs often associated with health promoting behaviors. Specifically, we found that blacks expressed greater concern about health. Women believed they tended to get sick more often and to suffer more severely from illness. Female and older respondents placed greater value on the kinds of services provided by members of the health professions. Female, black, older, and lower socioeconomic status respondents placed greater value on such healthful personal habits as exercise, alcohol avoidance, and proper diet. These results suggested that the poor health suffered by relatively disadvantaged members of society are not, in some manner, a consequence of fundamental beliefs about health.

\section{INTRODUCTION}

The health belief model attempts to explain the reasons why people engage in healthy behavior, make use of health care, or follow medical recommendations. 1.2 Those investigators who make use of the model argue that the choices people make in regard to health are mediated through several measurable psychological processes, here labeled general health concern, susceptibility, severity, benefits, and barriers. The first, general health concern, refers to the overriding willingness, eagerness, or tendency for an individual to make healthy

Support provided by the National Heart, Lung, and Blood Institute (Grant NO1-HN-92914).

John L. Weissfeld is with the Department of Internal Medicine, University of Michigan, Ann Arbor, Michigan.

John P. Kirscht is with the Department of Health Behavior and Health Education, University of Michigan, Ann Arbor, Michigan.

Bruce M. Brock is with Information Transfer Systems, Inc., Ann Arbor, Michigan.

Address reprint requests to Joel L. Weissfeld, MD. MPH, Ambulatory Care Section, Veterans Administration Medical Center, 2215 Fuller Road, Ann Arbor, MI 48105. 
choices, whatever the setting. Susceptibility refers to the degree to which an individual perceives and personalizes his risk of acquiring disease or risk of suffering the ill effects from existing disease. Severity refers to an individual's judgement regarding the impact of disease. once or if acquired, on his wellbeing. Finally, benefits and barriers refer to an individual's assessment of the value and costs (economic or otherwise) of the different health choices under consideration. The model presumes that health beliefs mediate the effects of other variables (e.g. . demographic variables) on the health choices people make.

The health belief model has been the subject of descriptive and explanatory studies.- Most studies investigate health beliefs in very selected population subgroups. Few choose to measure all components of the health belief model in the general population or attempt to describe the differences in health beliefs which characterize different portions of the population. In 1983, survey researchers at the University of Michigan measured health beliefs in a scientific sample of adults residing in Michigan. In this sample, we carefully examined health beliefs in the context of the health belief model. Further, we determined if important differences in health beliefs existed across definable subgroups of the general population.

We believe that the properties of health beliefs in the general population should interest investigators and practitioners concerned with health education. For example, the manner in which health beliefs distribute in the population may generate hypotheses which help to explain the origin of health beliefs. In practice, those who develop, deliver, or assess health education programs in the community may benefit from a better understanding of the peculiarities of fundamental health beliefs which characterize members of specific population subgroups. With this knowledge, for example, practitioners may be better prepared to tailor the content of health education messages intended for particular members of the community. For policy makers, the relationship between demographic factors and health beliefs may have wide implications. Despite public policies which attempt to equalize access to medical care, certain population subgroups (e.g., Blacks) share an inordinate burden of illness from behaviorly mediated diseases (i.e., heart disease, hypertension, cancer). ${ }^{3-6}$ Previous studies have examined differences in health behaviors (e.g., cigarette smoking, ${ }^{7}$ health care seeking in response to early symptoms of disease ${ }^{8.9}$ compliance with antihypertensive medications ${ }^{7}$ which may account for inequalities in the distribution of certain chronic diseases. In this article, we determine whether patterns of health beliefs among Michigan residents support the hypothesis that population subgroups with a larger burden of preventable chronic illness possess less favorable health beliefs.

\section{METHODS}

\section{Population}

In 1983, survey researchers from the University of Michigan measured blood pressure and collected other health information, including health beliefs, from adults residing in Michigan. A probability sample of households was selected by means of a multistaged, stratified cluster design. In each household, one adult 
(18 years of age or older) was selected at random. Communities with higher proportions of black residents were intentionally sampled more heavily. For this reason, the distributions observed differed from those which would have resulted from a complete census or simple random sample of the targeted population. In the following analyses, we identify those results which derived from the sampled observations directly and from the sampled observations weighted or adjusted for the peculiarities of the sample design.

In all, 2802 individuals, representing $74 \%$ of eligible households and $81 \%$ of households allowing the random selection of an adult respondent. consented to a personal interview. We excluded 54 nonwhite. nonblack individuals. Of the remaining 2748,388 subjects $(14.1 \%)$ were missing information on race $(0.3 \%)$, marital status $(0.2 \%)$, age $(0.2 \%)$, urban/rural designation of place of residence $(4.3 \%)$, education $(0.4 \%)$, and /or income $(10.1 \%)$. In analyses which considered race, age. marital status, urban/rural designation, education, and income simultaneously, these 388 observations were considered missing. Table 1 characterizes the 2360 respondents with information on all sociodemographic variables. Unadjusted values, as well as values adjusted for the sample's design, are shown. Distributions (adjusted for sample design) for gender, age, and marital status $(47.7 \%$ men, $50.0 \%$ aged $18-39$ years, $29.7 \%$ aged $40-59$ years, $20.3 \%$ aged $\geq 60$ years; $67.1 \%$ married; Table 1 ) were quite similar to those reported

Table 1. Characteristics of the Sample $(N=2360)$.

\begin{tabular}{|c|c|c|}
\hline & Percent & Percent" \\
\hline \multicolumn{3}{|l|}{ Gender } \\
\hline male & 43.6 & 47.7 \\
\hline female & 56.4 & 52.3 \\
\hline \multicolumn{3}{|l|}{ Race } \\
\hline white & 77.4 & 91.5 \\
\hline black & 22.6 & 8.5 \\
\hline \multicolumn{3}{|l|}{ Age } \\
\hline $18-39$ years & 50.9 & 50.0 \\
\hline $40-59$ years & 27.1 & 29.7 \\
\hline$\geq 60$ years & 22.0 & 20.3 \\
\hline \multicolumn{3}{|l|}{ Marital status } \\
\hline married & 55.5 & 67.1 \\
\hline unmarried & 44.5 & 32.9 \\
\hline \multicolumn{3}{|l|}{ Education } \\
\hline $0-11$ years & 24.7 & 21.4 \\
\hline 12 years & 37.1 & 39.1 \\
\hline$>12$ years & 38.2 & 39.5 \\
\hline \multicolumn{3}{|c|}{ Yearly family income } \\
\hline$<\$ 15,000$ & +9.1 & 38.5 \\
\hline$>\$ 15,000$ & 50.9 & 61.5 \\
\hline \multicolumn{3}{|c|}{ Character of residence } \\
\hline urban & 36.9 & 24.9 \\
\hline suburban & 39.4 & 44.3 \\
\hline rural & 23.6 & 30.8 \\
\hline
\end{tabular}

"Values are adjusted for the sample design. 
by the census $(47.2 \%$ men; $48.4 \%$ aged $20-39$ years, $30.4 \%$ aged $40-59$ years, $21.2 \%$ aged $\geq 60$ years; $65.6 \%$ married. ${ }^{10.11}$ When compared with census data, blacks and the less educated were underrepresented in the Michigan survey ( $8.5 \%$ vs. $13.2 \%$ black: $21.4 \%$ vs. $32.0 \%$ with less than a high school education). There may have been, as well, a tendency for respondents to the Michigan survey to underreport yearly family income (observed median income 16 thousand dollars, census median income $\$ 22,00(0)-25,000$.

Excluded individuals, when characterized with the data available, were more likely to be black, unmarried. older, female, urban dwelling, and poor. In addition, excluded individuals indicated a poorer state of health, more favorable health attitudes in some areas (general health concern, general health threat, and severity), and less favorable attitudes in other areas (susceptibility, medical benefits, and self-help benefits; see next section for definitions for these labels). In some analyses, urban designation of residence was disregarded and socioeconomic status defined in a manner which did not require the exclusion of individuals who preferred not to divulge their income. In these analyses, we minimized any bias which might have resulted from the exclusion of subjects with missing responses.

\section{Health Belief Measures}

We constructed scales from 32 questionnaire items which measured components of the health belief model (appendix)..$^{12-14}$ Responses were recorded on a closed, Likert format with four to six levels. Factor analyses identified six factors. ${ }^{14}$ The appendix lists the items and the six factors formed by the items.

We standardized each subject's response against the mean and standard deviation observed in the entire sample. Within each factor, nonmissing responses were averaged to form six scales. A missing value was assigned if all responses forming the scale were missing. Higher scores signified attitudes in the direction of scale labels. Therefore, higher scale scores signified attitudes which. according to the health belief model, favored healthful behavior. Reliabilities (coefficient omega $\omega^{15}$ ), ranged between 0.65 and 0.89 and were stable across univariate age, race, and sex subgroups. ${ }^{1+}$ We regarded reliability coefficients in excess of 0.65 as acceptable.

Items for three scales, labeled general health concern $(\omega=0.74)$, susceptibility $(\omega=0.77)$, and severity $(\omega=0.89)$, had content corresponding to the previously defined health belief model concepts with the same labels. Items forming two scales, labeled medical benefits $(\omega=0.72)$ and self-help benefit $(\omega=0.84)$, had content expressing the concepts benefits and barriers. Judging from item content, we believe the former scale, medical benefits, assessed valuations individuals placed on professional health care (e.g., physicians, medications. prescribed diets). The items which loaded most highly on the medical benefits scale were content specific for hypertension (appendix). The latter scale, self-help benefits, assessed valuations individuals placed on personal health habits (e.g.. nonsmoking, alcohol avoidance, exercise, and stress reduction). Susceptibility and severity scales contained items with content specific to common chronic illnesses of adulthood (e.g.. hypertension, heart disease, stroke). In 
contrast, the final scale, labeled general health threat $(\omega=0.65)$ assessed susceptibility and severity in the abstract, without disease-specific content.

In Table 2, we show the intercorrelations observed among these six health belief scales. The correlations shown were not adjusted for the sample design. The adjusted correlations, however, were similar. Three scales (general health concern, medical benefits, and self-help benefits) correlated relatively highly, while the remaining intercorrelations were less than 0.20 . This suggested that the three scales with high intercorrelations may have measured similar psychological concepts or constructs. Scale intercorrelations less that 0.20 were desired.

\section{Statistical Methods}

Distributions for several health belief scales were too heavily skewed to permit simple multiple linear regression. For this reason, we used multiple logistic regression to assess the independent association between a health belief scale and each of seven sociodemographic or health status variables. Multiple logistic regression has other advantages. The results of analysis (the adjusted odds ratio, see below) has a very intuitive interpretation. The so-called "loss" of information, which results from expressing the dependent variable in a dichotomous fashion, is not necessarily undesirable. For example, in a study of this size, statistically significant observations, with little substantive meaning, are often observed. The problem, in this study, and in others, is not the absence of statistically significant findings, but the presence of a sufficient number of findings to overwhelm one's powers of interpretation. The use of a more valid, albeit less sensitive, statistical method, does not detract from those findings which do achieve statistical significance.

We formed six dichotomous variables (the dependent variables in six separate multiple logistic regressions) by division of the study population at the median for a health belief scale. We used the odds ratio (the odds of favorable health beliefs for members of a "risk" group divided by the odds of favorable health beliefs for members of the comparison group) to express the strength of association between a sociodemographic or health status variable and a health belief. Odds ratios greater than one indicated that members of the "risk" group were more likely to express favorable health beliefs. Odds ratios less than one had the opposite interpretation.

Table 2. Observed Correlations among Six Health Belief Model Scales.

\begin{tabular}{lccccc}
\hline & $\begin{array}{c}\text { General } \\
\text { Health } \\
\text { Threat }\end{array}$ & Susceptibility & Severity & $\begin{array}{c}\text { Medical } \\
\text { Benefits }\end{array}$ & $\begin{array}{c}\text { Self-Help } \\
\text { Benefits }\end{array}$ \\
\hline General health concern & 0.04 & $0.07^{\mathrm{a}}$ & $0.16^{\mathrm{a}}$ & $0.20^{\mathrm{a}}$ & $0.34^{\prime \prime}$ \\
General health threat & & $0.19^{\mathrm{a}}$ & $0.08^{\mathrm{a}}$ & -0.04 & 0.04 \\
Susceptibility & & & $0.10^{\mathrm{a}}$ & -0.05 & 0.02 \\
Severity & & & & $0.11^{\mathrm{a}}$ & $0.13^{\prime \prime}$ \\
Medical benefits & & & & & $0.35^{\mathrm{a}}$ \\
\hline
\end{tabular}

${ }^{.} p<0.001$. 
We entered the following independent variables into logistic regressions: race (black/white), gender (female/male), age ( $\geq 60,40-59,18-39$ years), marital status (unmarried/married). urban characterization of residence (rural/suburban/urban), socioeconomic status, and perceived health status.

We examined several different measures of socioeconomic status. In the principal analysis, we took the sum of completed years of education (scored () for less than high school. 1 for high school, and 2 for greater than high school) and yearly family income (scored 0 for less than the median income and 1 for greater than the median income). This formed a socioeconomic variable with four levels. Because of missing information on income, this particular measure of socioeconomic status resulted in the exclusion of a significant fraction of the study population. For this reason, we compared analyses which employed alternative measures of socioeconomic status. One measure categorized education into quartiles (scored 0 for $0-11$ years, 1 for 12 years, 2 for 13 years, and 3 for $\geq 14$ years). Another measure categorized income into quartiles (scored 0 for $\$ 0$ $8.000,1$ for $\$ 9.000-14.000 .2$ for $\$ 15.000-18.000$, and 3 for $19.000-65.000)$. The sum of education and income. so defined, provided a final measure of socioeconomic status. However, if data for education or income (but not both) were missing, this final measure (which assumed values from 0 to 6) took a value equal to twice the value of the component measure with available data.

Questionnaire items included ratings of personal health, success in maintaining personal health. and personal health relative to others of similar age. The mean, nonmissing. response to these items (each scored on a five-category scale) formed a perceived health status scale. We regarded perceived health status as a global measure, correlating with more objective measures of physical, mental and social health. ${ }^{16.17}$ Logistic regressions compared the odds of favorable health beliefs among individuals with poor and good health, distinguished at the median for the perceived health status scale.

\section{RESULTS}

Table 3 summarizes the principal results. Table 3 expresses in the form of odds ratios, the associations between each of seven sociodemographic or health status variables (the independent variables) and six health beliefs (the dependent variables, these taken individually). Multivariable statistical methods were used to adjust the odds ratios assigned to each independent variable for the simultaneous effects of other independent variables. The results in Table 3 are not adjusted for the design of the sample. This adjustment, however, did not change the results we observed.

Stated briefly, women perceived greater health threat, more confidence in medical care, and greater value in healthful personal habits. Blacks expressed great health concern and stronger belief in healthful personal habits. Middleaged and older individuals placed greater value on medical care and on healthful personal habits. Health beliefs and urban character of residence were unrelated. Individuals with high socioeconomic status appeared to place slightly lower value on healthful personal habits. Individuals who regarded themselves in poor health reported greater susceptibility (in response to questions with and without disease- 
Table 3. Logistic Regression Analysis: Association between Seven Sociodemographic or Health Status Variables and each of Six Health Bclicfs."

\begin{tabular}{|c|c|c|c|c|c|c|c|}
\hline & & \multicolumn{6}{|c|}{ Health Belici Scalk } \\
\hline & & $\begin{array}{l}\text { Ceneral } \\
\text { Health } \\
\text { Concern }\end{array}$ & $\begin{array}{l}\text { Generil } \\
\text { Health } \\
\text { Threalt }\end{array}$ & $\begin{array}{l}\text { Suscept- } \\
\text { ihility }\end{array}$ & Severity & $\begin{array}{l}\text { Medical } \\
\text { Benefits }\end{array}$ & $\begin{array}{l}\text { Self-Help } \\
\text { Benefits }\end{array}$ \\
\hline \multicolumn{8}{|l|}{ Sample" } \\
\hline size & & 2360 & 2330 & 2322 & 2.348 & 2360 & 2359 \\
\hline \multirow[t]{2}{*}{ Sex } & (men) & & & & & & \\
\hline & $\begin{array}{l}\text { women } \\
\text { (white) }\end{array}$ & 1.14 & 1.64 & 0.98 & 1.02 & $1.40^{\circ}$ & $2.38^{\mathrm{c}}$ \\
\hline Race & black & $2.80^{\prime}$ & 0.69 & 0.97 & 1.47 & 1.13 & $2.08^{\circ}$ \\
\hline \multirow[t]{3}{*}{ Age } & $(18-39)$ & & & & & & \\
\hline & $4(1-59$ & 0.79 & 0.82 & 1.22 & 0.87 & 1.17 & 1.45 \\
\hline & $\geq 60$ & 0.84 & 0.73 & 0.93 & 0.88 & $1.70^{c}$ & 1.18 \\
\hline \multirow{5}{*}{$\begin{array}{l}\text { Marital } \\
\text { status } \\
\text { Urbanicity }\end{array}$} & (married) & & & & & & \\
\hline & unmarried & 1.04 & 1.10 & 1.09 & 1.15 & 0.90 & 0.79 \\
\hline & (urban) & & & & & & \\
\hline & suburban & 0.81 & 1.15 & 0.92 & 0.79 & 0.94 & 0.82 \\
\hline & rural & 0.71 & 1.15 & 0.95 & 0.85 & 0.94 & 0.76 \\
\hline \multirow{4}{*}{$\begin{array}{l}\text { Socioeconomic } \\
\text { status }\end{array}$} & $(0)$ & & & & & & \\
\hline & 1 & 0.93 & 0.98 & 0.84 & 0.99 & 0.88 & 1.14 \\
\hline & 2 & 0.75 & 0.89 & 0.66 & 1.01 & 0.90 & 1.00 \\
\hline & 3 & 0.72 & 1.03 & 0.58 & 1.10 & 0.71 & 0.64 \\
\hline \multirow{2}{*}{$\begin{array}{l}\text { Health } \\
\text { status }\end{array}$} & (good) & & & & & & \\
\hline & poor & $0.68^{\circ}$ & $2.56^{\circ}$ & 2.40 & 1.16 & $0.7 I^{\circ}$ & 0.85 \\
\hline
\end{tabular}

"Associations are expressed in the form of the odds ratio. i.e. the odds of favorable health benefits among members of the "risk" groups divided by the odds of favorable health benefits among members of the comparison group. Labels for the comparison groups are enclosed in parentheses.

"Sample sizes vary because of missing data for the dependent variables.

$p<0 .(0) 1$.

specific content. the susceptibility and general health threat scales, respectively), but less health concern and less confidence in the value of medical care.

In addition, we conducted analyses that disregarded urban character of residence and which replaced socioeconomic status with educational status. These analyses avoided the exclusion of subjects because of missing information on character of residence or on income. Here, depending on the health belief in question, sample sizes ranged between 2659 and 2716 (out of 2748 eligible). As far as sex, race, age, marital status, and health status were concerned, the pattern of statistically significant findings was identical to that shown in Table 3 . We observed a statistically significant $(p<0.001)$ negative association between educational level and the belief that one is susceptible to specific chronic illnesses of adulthood (the susceptibility scale). Individuals with more education tended to place less value on healthful personal habits. This finding did not achieve statistical significance, but corresponded to the statistically significant observation that individuals with high socioeconomic status appeared to place less value on healthful personal habits (Table 3 ).

We also conducted a series of analyses which, again, disregarded character of residence, but which employed an alternative measure of socioeconomic status. This particular measure. a composite of education and income, did not require the presence of information for both education and income. Here, again depending on the health belief in question, sample sizes ranged between 2673 
and 2730 . These analyses confirmed the statistically significant finding reported in Table 3. Two additional observations achieved a significance level of 0.001 . Blacks were more likely to feel that several specific adulthood diseases could pose a serious problem for them (the severity scale, adjusted odds ratio 1.66). Blacks, however, believed they became sick less often and suffered less severely from illness (the general health threat scale, adjusted odds ratio 0.64). As a whole, the consistency of these results indicated that exclusion of individuals because of missing information did not produce substantial bias in the values shown in Table 3.

Although not necessarily significant in a statistical sense, individuals with higher socioeconomic status appeared to possess what might be regarded as less desirable health beliefs (the general health concern, susceptibility, medical benefits, and self-help benefit scales. Table 3 ). For this reason, we examined the association between socioeconomic status and health beliefs in more detail. We compared the average value for each health belief scale across subgroups categorized according to several measures of socioeconomic status. The method of direct standardization was used to adjust health beliefs for race, sex, and perceived health status. We used the sample distribution for race, sex, and perceived health status (adjusted for sample design) as the reference population in the direct standardization. We used analysis of variance to examine the statistical significance of observed differences in the health beliefs across socioeconomic class.

The results for a composite measure of socioeconomic status are shown in Table 4. When not adjusting for sex, race, and health status, we observed a negative relationship between high socioeconomic status and favorable scores on the general health concern, general health threat, susceptibility, and selfhelp benefits scales. We observed a trend in the opposite direction for the severity scale. In some cases (general health concern, general health threat, and susceptibility), adjustment for sex, race, and health status appeared to blunt the association between a belief and socioeconomic status. Results were similar when health beliefs were compared among subjects categorized solely on the basis of yearly family income or education. Trends, however, were more apparent when subjects were stratified according to income. Although differences in health beliefs were relatively small, the results of these more straight forward analyses appeared to confirm the results of the multivariable analyses shown in Table 3.

\section{DISCUSSION}

In this study, markers of social disadvantage (female, black, older, and low socioeconomic status) appeared to associate with what, in the context of the health belief model, might be regarded as favorable health beliefs. These associations were adjusted for perceived differences in health. For this reason, elevated health concern among blacks, for example, cannot be attributed simply to a perceived state of poor health. (Black and poor perceived health were associated with an odds ratio of $1.7(p<0.01)$.) A more detailed examination of the results suggested that each health belief may possess a relatively unique profile of sociodemographic correlates. Blacks, for example, report greater health 


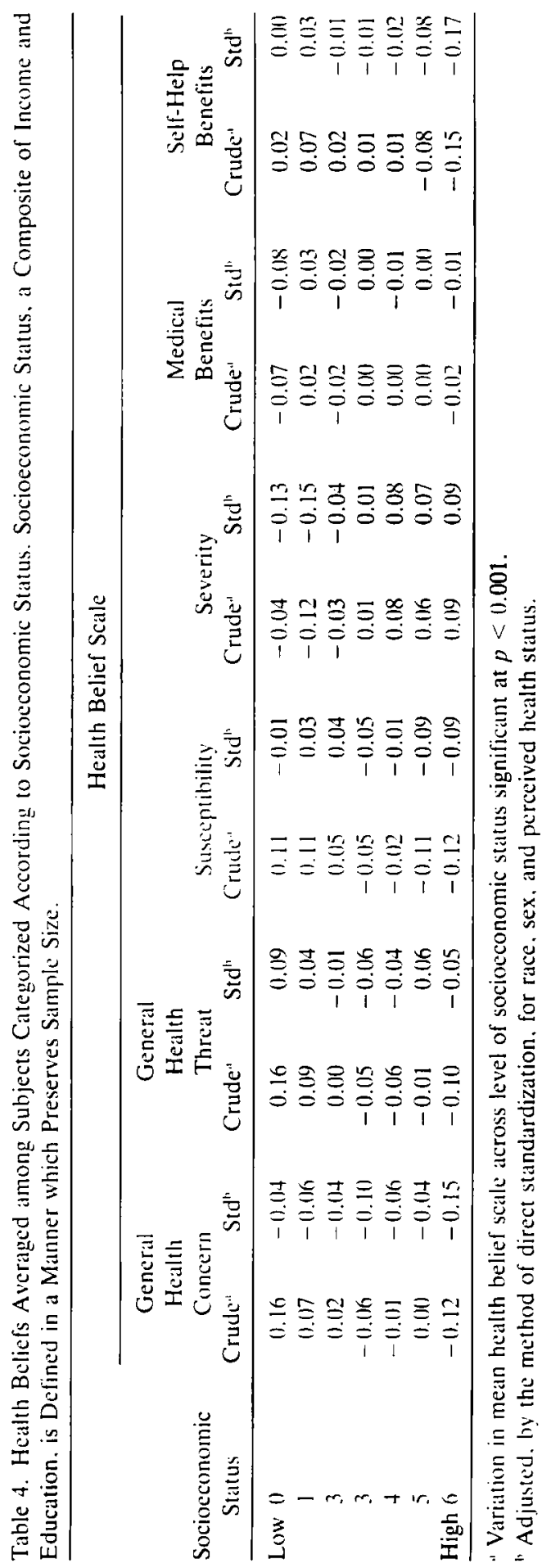


concern, women greater health threat, and older individuals greater confidence in the benefits of medical care. Female, black, older, and lower socioeconomic status individuals all appeared to place value on health promoting personal habits.

Few publications address demographic correlates of health belief model components. Kirscht et al. ${ }^{18}$ in a nationwide sample of 1493 adults, observed that female. lower socioeconomic status, and younger individuals felt more susceptible to disease. In a 1980 . Illinois health survey, blacks and less educated individuals reported attitudes which expressed greater disease susceptibility and severity. ${ }^{19}$ In a national survey administered to 2839 adults, ${ }^{211}$ women and respondents with lower socioeconomic status reported greater "worry about health," a question with a general health concern interpretation. In a 1979 National Center for Health Statistics survey with 3025 respondents. ${ }^{21}$ female, less educated. and older individuals reported greater "worry over health." Women and the better educated reported stronger belief in the ability of individuals to prevent hypertension. The Health Perception indexes, developed by Davies and Ware for the Rand Health Insurance Experiment,,$=$ contained scales with health belief model interpretations. Here, women, nonwhite, less educated, and lower income participants expressed greater susceptibility to disease (the Resistance and Health Outlook scales from the Health Perception indexes). Nonwhite, less educated, and lower income individuals reported a greater concern about health (the Health Worry/Concern scale).

Despite differences in questionnaire items and target populations, previous surveys and the Michigan survey have produced consistent results. Female, nonwhite. less educated, and lower income individuals consistently expressed greater concern about health and greater susceptibility to the ill effects of disease. Relatively few studies have addressed relationships between demographic factors and attitudes on the benefits of medical care or personal health habits. In the Michigan survey, markers of social disadvantages associated with favorable attitudes regarding the value of healthful personal habits.

In the Michigan survey, we observed strong associations between perceived health status and other health beliefs. For example, we observed a strong association between perceived poor health and health threat and between perceived poor health and disease susceptibility (Table 3). The general health threat and susceptibility scales, in a sense, intended to elicit expectations regarding future states of health. Individuals probably based these expectations on perceptions of present health. ${ }^{17}$ Ironically. perhaps, individuals in poor health (subjectively), despite (on average) enhanced perceptions of health threat and disease susceptibility, manifested lower levels of health concern and less confidence in the value of professional medical services. To explain this observation, we speculate that most respondents in this general population sample were relatively well from a standpoint of physical and social functioning, whatever the perceived state of general health. ${ }^{23}$ Reports of poor health are probably based on relatively mild ailments, on disease processes (e.g. , hypertension) which, as yet, have not produced significant functional disability, or on sources of social or psychological distress (e.g. unemployment) which are not subject to medical benefit. 23 Similarly, individuals who base perceptions of poor health on problems which may have little functional impact, may have experienced little cause for conern about 
their health. Alternatively, lack of health concern among the truly health impaired may represent a psychological defense against mental anguish from the effects of ill health.

In general, social groups define health differently. ${ }^{24}$ Self-reports of health status are expected to differ according to social grouping, even in the absence of objective differences in physical health. For example, individuals belonging to social groups, characterized by relative stoicism, may be less likely to report prevalent, relatively mild, ailments as manifestations of poor personal health. Thus, given the potential importance of associations (whether real or perceived) among demographic factors and health status, we adjusted associations between health beliefs and other factors for differences in perceived health status.

Controlled for perceived health and other sociodemographic variables, women in Michigan perceived greater general health threat and greater value in medical care and in healthful personal habits. Previous research demonstrates that women are relatively heavy consumers of health services. ${ }^{. ~ D i f f e r e n c e s ~ i n ~ h e a l t h ~ c a r e ~}$ utilization between men and women are only partly explained by perceived or actual differences in health status (i.e., "need" for medical care). At the aggregate level, the correspondence, for women, between health beliefs and health care utilization, provides some degree of validation for the health belief model or, alternatively, some explanation for differences in health care use according to gender. We speculate that such health beliefs derive from a dominant social learning process for men and women. A sense of invulnerability, toughness, or immunity from illness may be part of the definition of the male role in society. Further research should determine whether the relationship between gender and health beliefs is similar across other sociodemographic groupings.

In this sample, blacks were more likely to express a high level of general health concern and to place a high value on healthful personal habits. The association between race and general health concern was independent of other sociodemographic factors, most importantly perceived health status, socioeconomic status, and urban characterization of place of residence. Nevertheless, race, in a multivariable and statistical sense, may still be functioning as a potent social stratification variable. Individuals with low social status may have more reason to be "concerned" or to be "worried" about health. The manifestation of poor health, whether in the form of physical or mental disability or in the form of signs of "social" problems (urban blight, violent crime, unemployment, pollution), may be a more dominant feature of the environment of blacks. Conceptually, at least, one would think that measures of disease severity would more closely capture concerns regarding the ill effects of disease. We observed, however, that black race is the sociodemographic factor which associates most strongly with perceptions of disease severity (odds ratio 1.47, Table 3). The general health concern scale contained one item (item 4 , appendix) which measured "concern" over the possible health effects of high blood pressure. The high prevalence of hypertension among blacks has been a focus of many public health education efforts. ${ }^{25}$ Scores on the general health concern scale may reflect appropriate responses, by blacks, to the one item in the scale dealing with blood pressure. With blacks, the estimated reliability and the percent of variance, in the entire pool of health belief questionnaire items, explained by the general health concern factor, were slightly lower ${ }^{1+}$ These observations suggested that 
the general health concern scale may be a less valid measure, in blacks, of the health belief model component in question. That is, the association between race and general health concern may reflect. in part. a methodological artifact in that the scale in question may not be measuring the same thing in different racial groups.

The association between older ages and favorable attitudes regarding medical care and healthful personal habits generates two classes of hypotheses. First, this cross-sectional association may reflect a cohort phenomenon. That is, older and (to a lesser extent) middle-aged individuals may have developed their attitudes during earlier time periods, during which dominant beliefs regarding health were different. Alternatively, associations among age and attitudes regarding medical care and health habits may reflect a more intrinsic property of age and the aging process. Perhaps, with age, by virtue of accumulated direct and indirect experience. comes increased awareness of the association between health habits and health outcomes. Serial cross-sectional studies performed over different time periods or longitudinal studies could distinguish these two processes.

Finally, the negative association between socioeconomic status and belief in healthful personal habits (Table 3 ) runs contrary to any expected health advantage enjoyed by the well to do. Despite controlling for other demographic factors. we observed negative gradients between socioeconomic status and health concern, disease susceptibility, and belief in the medical care (Tables 3 and 4). Cockerham et al. observed, even after adjustment of health status, a negative association between income and belief in the need to see a physician for various symptoms. ${ }^{26}$ The authors interpreted this finding as an indication that lower income people were more dependent on the medical care system.

As with any study based on survey data, one must temper inferences against certain unavoidable methodological limitations. In this particular analysis, problems associated with multiple comparisons were alleviated by limiting inferences to those observations which achieved a high level of statistical significance. The possibility that the validity of the health belief measures varied systematically according to sociodemographic characteristics cannot be excluded. The health belief measures chosen for analysis, however, appeared to have roughly equivalent psychometric properties when compared by race, sex, or age. ${ }^{1+}$ When examining large data sets, one can not judge the substantive importance of any observation simply on the basis of statistical significance. However, some of the associations in question appeared strong (greater than twofold increase in odds. Table 3). In addition, the presence of independent associations between a health belief and each of several demographic variables can be used to define subgroups with extreme health beliefs. For example, sex, race, age, and socioeconomic status each had an incremental relationship with self-help benefit (Table 3). Thus, these analyses suggested that young black women in the lowest socioeconomic grouping would have a high prevalence of favorable attitudes on the benefit of healthful personal habits. Finally, the chosen analytic strategy, which dichotomized variables measured on a continuous scale, may have attenuated associations. Given all the above, we believe that associations reported in this article reflect an important process and not simply the power of large numbers.

In sum, though cross-sectional, these analyses paint a coherent picture. De- 
mographic variables, construed in the very broadest sense as markers of social disadvantage, were associated with health beliefs which, according to a popular model of health psychology (the health belief model), facilitate healthful behavior. With few exceptions, the socially disadvantaged (lower socioeconomic and black respondents. in particular) were not characterized by attitudes which reflected a lack of concern about health or a disregard for the value of medical care or of healthy life styles. These observations may indicate the potential limitations of community health education activities, directed toward the poor, which attempt simply to enhance fundamental or general health attitudes. Successful community health promotion ventures may need, as well, to address the structural barriers to good health which characterize social disadvantage (e.g., poor access to medical care). Or. such ventures may need to take a more behavioral approach and attempt to assess and to enhance directly health promoting behaviors (c.g. teaching skills which improve medication compliance). The specific content of health education messages may need to focus more squarely on "skills training" regarding specific behaviors. Health education activities limited to the traditional health beliefs (e.g. beliefs in the health hazards of smoking and the benefits of quitting) may not be adequate.

\section{APPENDIX. HEALTH BELIEF MODEL QUESTIONNAIRE ITEMS AND FACTOR LOADINGS (FROM FACTOR ANALYSIS, OBLIMIN ROTATION) ${ }^{14}$}

\begin{tabular}{lr} 
Fuestor \\
Loading \\
\hline
\end{tabular}

General Health Concern

1. How often do you think about your health?

2. How concerned are you about your health?

3. How important do you think it is that people take special care of their health?

4. How concerned are you about the possible future effects of high blood pressure on your health? How concerned are you about health problems that high blood pressure could cause for you?:

General Health Threat

5. Compared to other people your age, would you say that you get sick much more often ... ?

6. Compared to other people your age. when you do get sick, would you say you get much more sick... ?

Susceptibility

7. How likely do you think it is that you will get high blood pressure sometime in your life? One year from now, how likely do you think it is that you will have elevated blood pressure levels where your pressure is not in good control?"

8. How likely is it that you will have a heart attack in the future?

9. How likely is it that you will have a stroke in the future?

10. How likely is it that you will have kidney disease in the future? 
Factor

Questionnaire Items

Loading

11. How likely is it that you will have cancer in the future?

0.50

Severity

12. How serious a health problem would high blood pressure he for you? How serious a health problem do you think high blood pressure will be for you in the future?:

13. How serious a health problem would having a heart attack be for you?

14. How serious a health problem would having a stroke be for you? 0.74

15. How serious a health problem would having kidney disease be for you? 0.66

16. How serious a health problem would having cancer be for you?

Medical Benefits

17. Overall, how helpful are doctors when you are ill?

18. Overall, how effective do you think medical treatment is in preventing illness from the effects of high blood pressure?

19. Overall, how effective do you think blood pressure medicines are in preventing illness from the effects of high blood pressure?

21. What about exercise programs for high blood pressure?

0.38

22. How important do you think controlling high blood pressure is?

0.18

23. Overall, how easy or difficult is it to get medical care when you want it?

0.18

\section{Self-Help Benefits}

Now I'll read you a list of things some people think help their health.

Tell me if you think each one I read helps a person's health a great deal....?

24. ... eating a balanced diet?

25. ... getting regular physical activity?

26 . . . being at the ideal weight for a person's height? $\quad 0.47$

$27 . .$. avoiding getting tense and anxious?

28. . . getting regular medical checkups? 0.46

29 . . . getting the right amount of sleep? $\quad 0.57$

$30 . .$. avoiding cigarettes'? $\quad 0.53$

31. . . avoiding alcohol? $\quad 0.59$

32. . . . leading a spiritually good life? $\quad 0.49$

`Alternative questions for respondents with a history of high blood pressure.

\section{References}

1. Becker $M(e d)$ : The health belief model and personal health behavior. Health Education Monographs 2:324-508, 1974.

2. Janz NK, Becker MH: The health belief model a decade later. Health Education Quarterly 11:1-47, 1984.

3. Gillum RF, Grant CT: Coronary heart disease in black populations: II. Risk factors. Am Heart J 104:852-864. 1982.

4. Gillum RF: Coronary heart disease in black populations. I. Mortality and morbidity. Am Heart J 104:839-851, 1982.

5. Persky V, Pan WH. Stamler J, Dyer A. Levy P: Time trends in the US racial difference in hypertension. Am J Epidemiol 124:724-737, 1986. 
6. Rowland ML. Fulwood R: Coronary heart disease risk factor trends in blacks between the first and second National Health and Nutrition Examination Surveys, United States, 1971-1980. Am Heart J 108(Pt 2):771-779. 1984.

7. Folsom AR, Gomez-Marin O. Sprafka JM, Prineas RJ, Edlavitch SA, Gillum RF: Trends in cardiovascular risk factors in an urban black population. 1973-74 to 1985: The Minnesota Health Survey. Am Heart J 114:1199-1205, 1987.

8. Berkanovic E, Telesky C, Reeder S: Structural and social psychological factors in decisions to seek medical care for symptoms. Med Care 19:693-709, 1981.

9. Hulka BS, Wheat JR: Patterns of utilization: The patient perspective. Med Care 23:438-460, 1985.

10. Statistial Abstract of the United States, 1982-1983. U.S. Department of Commerce (Bureau of the Census), 1984.

11. A Statistical Abstract Supplement-State and Metropolitan Area Data Handbook, 1986. U.S. Department of Commerce (Bureau of the Census), 1986.

12. Jette AM, Cummings M. Brock BM. Phelps CM, Naessens J: The structure and reliability of health belief indices. Health Services Research 16:81-98, 1981.

13. Maiman LA. Becker MH. Kirscht JP. Haefner DP. Drachman RH: Scales for measuring health belief model dimensions: A test of predictive value. internal consistency, and relationships among beliefs. Health Education Monographs 5:215-230, 1977.

14. Weissfeld JL, Brock BM, Kirscht JP, Hawthorne VM: Reliability of health belief indexes: Confirmatory factor analysis in sex, race, and age subgroups. Health Serv Research 21:777-793, 1987.

15. Carmines EG, Zeller RA: Reliability and Validity Assessment. Beverly Hills, CA: Sage Publications, Inc., 1979.

16. Bergner M: Measurement of health status. Med Care 23:696-704, 1985.

17. Ware JE: The assessment of health status. in Aiken LH. Mechanic D. (eds): Applications of Social Science to Clinical Medicine and Health Policy. New Brunswick, NJ: Rutgers University Press, 1986. pp. 204-228.

18. Kirscht JP. Haefner DP. Kegeles SS. Rosenstock IM: A national study of health beliefs. J Health Human Behav 7:248-254. 1966.

19. Sharp K. Ross C. Cockerham WC: Symptoms, beliefs, and the use of physician services among the disadvantaged. J Health Soc Behav 24:255-263, 1983.

20. U.S. Department of Commerce: A National Study of Health Practices and Opinion. National Technical Information Service (PB 210978). June 1972.

21. National Center for Health Statistics: Highlights from Wave l of the National Survey of Health Practices and Consequences (DHHS Pub No (PHS) 81-1182).

22. Davies AR, Ware JE: Measuring Health Perceptions in the Health Insurance Experiment. Santa Monica. The RAND Corporation, 1981.

23. Barsky AJ: The paradox of health. NEJM 318:414-418, 1988.

24. Mechanic D: Future Issues in Health Care: Social Policy and Rationing of Medical Services. New York, The Free Press, 1979.

25. Apostolides AY. Cutter G. Kraus JR, et al.: Impact of hypertension information on high blood pressure between 1973 and 1978. Hypertension 2:708-713, 1980.

26. Cockerham WC, Kunz G, Lueschen G and Spaeth JL: Social stratification and selfmanagement of health. J Health Human Behav 27:1-13. 1986. 